\title{
An evaluation of Top Notch fundamental A and B
}

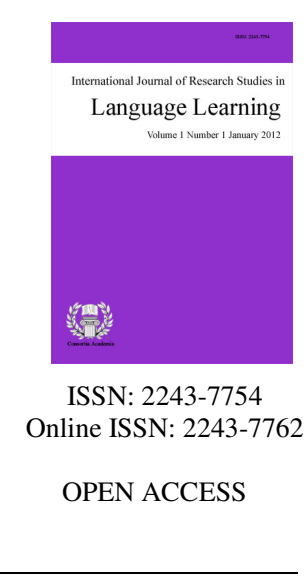

Tavakol, Mahboobeh

Department of English, Science and Research branch, Islamic Azad University, Yazd, Iran (mahboobehtavakol@yahoo.com)

\section{Sayadian, Sima}

Department of English, Meybod branch, Islamic Azad University, Meybod, Iran (sayadian.sima@maybodiau.ac.ir)

\section{Abstract}

Adopting the appropriate textbook is a controversial task for second/foreign language teachers. In Iranian EFL situation where the teachers are not usually textbook providers but just consumers of other people's material, there might be a need to evaluate the available EFL textbooks and investigate their contribution to general English courses. This paper aims at evaluating Top Notch fundamentals in terms of their impact on Iranian learners' communicative and pragmatic competence. It is based on a comparison between Top Notch and Introductory Interchange (third edition) (Intro Interchange afterwards) to evaluate the extent of their applicability for schools and institutes' communicative EFL courses. A checklist consisting of 38 items is also provided and distributed among seven raters who had the experience of teaching Top Notch Fundamentals and Intro Interchange. The results of the completed checklists are added to the related sections. This step by step comparison has revealed that both textbooks are almost the same in most parts. In fact, it must be notified that while they are appropriate to be applied for communicative English courses and provide the learners with enough authentic input and opportunity to promote four major skills, they suffer from several drawbacks. Finally it is concluded that Top Notch is only appropriate to be practiced in general English courses in foreign language institutes; however, Interchange as a dominating EFL textbook regardless of all its deficiencies, is flexible enough to be used, as it has been successfully for years, in both foreign language institutes and schools in Iran.

Keywords: evaluation; EFL; checklist; top notch; CLT; interchange 


\section{An evaluation of Top Notch fundamental A and B}

\section{Introduction}

Textbooks play a crucial role in the realm of teaching and learning. They are considered as the most observable and after teacher, the most important part of the foreign language classroom. The global status of English is manifested in a huge textbook publication industry. In Iran several EFL textbook series are available most of which aims at preparing learners for international communication. When different options of varying features are available on the market, evaluation becomes important to provide teachers with an appropriate textbook selection process. Sahragard et al. (2009) have conducted an in-depth evaluation of Interchange series, as communicative and task based series and contend that Interchange is not completely along with the objectives intended for it. Whereas the prominent study by Soleimani and Dabbaghi (2012) has reflected the efficiency of the New Interchange course books in terms of providing sufficient pragmatic input to fulfill the basic communicative needs of the Iranian EFL learners which is harmonious with findings of the present study.

Ultimately, Birjandi and Alizadeh as the leading experts in the field, has endeavored to compare three dominating EFL/ESL textbook series namely, Top notch, Interchange, and English files series utilized by language institutes targeted in Iran, in their outstanding article. Employing a validated checklist they have compared the textbook based on twelve distinct skills including: comprehension, application, analysis, synthesis, evaluation, deduction, induction, balanced-thinking, multiple perspective-taking, creative thinking, building community of thinkers, and knowledge, each contributing in a specific way to the overall efficiency of a textbook and came up with the insight that all the three mentioned textbooks mainly tapped knowledge, comprehension, application and building community of thinkers skills while failed to acceptably include other skills reported to be of utmost importance for students' academic success. They maintained that amongst the textbooks, Except for lower order thinking skills, Top Notch is reported to be marginally higher in other skills. Notwithstanding the fact that the abovementioned studies make an infinitesimal part of the studies in this area, they have considerable implications for the present comparative-descriptive study. Throughout this article Top Notch as a rather popular communicative EFL/ESL textbook, is evaluated from different aspects. This attempt is manifestly a more synthesized view on textbook evaluation based on a comparison between Top Notch fundamentals and their strong, influencing competitor, Intro Interchange (third edition) which has dominated the EFL market for many years.

\section{Methodology}

\subsection{Design}

This descriptive-analytical study is quantitative in nature and enjoys a comprehensive framework. It aims at providing an eye-opening comparison between the two influential EFL/ESL textbook series which has been predominately used in Iranian EFL context, namely, Intro Interchange and Top Notch fundamentals A\&B. The results of the comparison are fully described using simple statistics.

\subsection{Participant}

A total of seven raters with at least two-year experience of teaching both Top Notch and interchange were selected to participate in this study. The participants were presented with a checklist of EFL/ESL textbook evaluation, and were clearly directed to rate the textbooks based on the criteria included. While the raters were mostly more experienced in teaching Intro Interchange, they were supposed to rate the textbooks based on what they perceived to be the best for textbook's qualification regarding to each criterion, therefore the inequality of 
An evaluation of Top Notch fundamental A and B

their experience would not serve as a source of bias. It must be noted that the researcher (who has introspectively reported the descriptive data) has the experience of teaching both of the textbooks to Iranian EFL learners.

\subsection{Instrumentation and Procedure}

An EFL/ESL textbook evaluation checklist consisting of 38 items served the instrument in the present study. The checklist was compartmentalized into seven sub-parts, each directly related to a criterion and likewise, an important aspect of textbook evaluation. The raters are directed to rate the textbooks separately for each criterion and its related questions honestly and free from bias or prejudice. The questions were quite clear and straightforward and they were rated based on a five point Likert scale (from o-not at all, to 4-completely). Though for the most part of the study, the data is descriptive and the result of the researcher's introspective analysis and evaluation of the textbooks in relation to each other, statistical data in terms of the mean score obtained from the checklist is added to the body for the purpose of comparison and likewise the verification of the data reported by the researcher. The percentages obtained from each table is described clearly and explained in terms of each criterion for the textbooks.

\section{The Study}

Top Notch is a six-level communicative English course for adults and young adults with two beginning entry levels, which aims at bringing the students to a "Top Notch" level of communicative competence. The main focus of this article is on the detailed evaluation of this course book in terms of ten major criteria including:

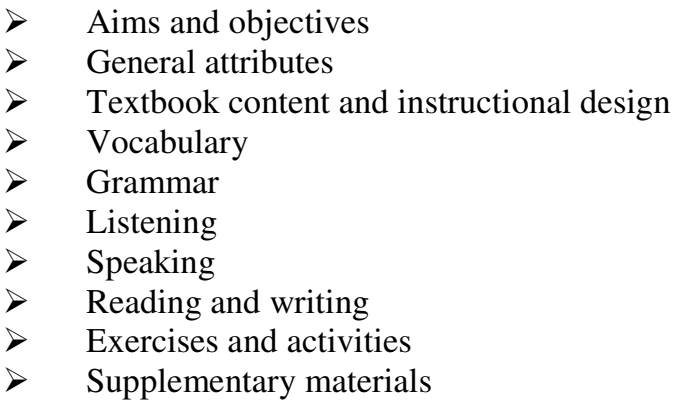

These criteria are given priority based on their contribution to the whole procedure of textbook evaluation and their significance in promoting the usefulness and validity of a textbook. In parallel, Intro is also evaluated based on the same criteria and the main objective of the comparison between the textbooks is to suggest the one which is more beneficial and optimizing for Iranian EFL context. A 38-item checklist which appended to the paper is also used to be completed by seven raters with the experience of teaching the aforementioned textbooks. The total scores on each criterion are computed to provide useful data on raters' evaluation. The results are illustrated in tables by the end of each section. In conclusion, there must be a subtle judgment as which textbook is more appropriate to be used in Iran's institutes and schools.

\subsection{Aims and objectives of the textbook:}

When instructors decide to choose a textbook for a specific course of instruction, certainly they start from searching about all the materials available on the market. In order to choose the appropriate textbook they will consider those options which on the one hand match the course objectives and the length of the course and on the other hand are ideal for the learners and the teaching situation. As it was mentioned, this study tries to evaluate Top Notch as an EFL textbook to see whether it is appropriate for being taught in a general four-skill course in Iranian EFL context. To evaluate the aims and objectives of an EFL textbook and parallel them with the course and learner's objectives, it is a good idea to investigate its author's views about the nature of language and the nature of language learning. The first step to appraise Top Notch and its pedagogical implications for Iranian EFL context is to decide from the aims and objectives it reflects and the approach(s) it takes for teaching English 
Tavakol, M. \& Sayadian, S.

as a foreign language.

Joan Saslow and Allen Ascher have considered one main objective for Top Notch series, say, to prepare the learners for international communication. In fact it claimed that the learners would be prepared to interact with native and non- native speakers of English, in other words, English is treated as a lingua franca. So if the textbook explicitly claims a "Top Notch" communicative competence for students as its main objective it could be amongst the options to be applied as a general English course' material. To achieve this objective Top Notch has provided the learners with lessons designed for communication goals along with the controlled or free practices at the end of each lesson and social language which expose the learners to authentic, natural English. In Interchange, on the other hand, nothing is mentioned about communicative or pragmatic competence and it does not introduce an explicit objective but instead claims to provide the learners with opportunity to learn and practice the four major skills of listening, speaking, reading and writing in addition to vocabulary and pronunciation. To reach this objective all the units are divided into sections and each section follows a specific goal with the overall units maintaining the same goal i.e. promoting four major skills.

Intro Interchange and Top Notch Fundamentals set general goals; however, Top Notch more explicitly introduces communicative competence as its main objective which is in congruence with the objective of the general courses. More important than citing the objectives is a concise, up-to-date method suggested by the textbook to reach the addressed objectives. In both cases the teacher's manual provides the teachers with enough guidance to teach each unit systematically in order to reach the objectives addressed by the textbook. In the case of intro there are several suggestions to teach each section of the unit which is utilizing for the learners and optimize the learning process. Of course it must be noted that some suggestions are not applicable specially in Iran that the EFL classes are not merged, and they are just a waste of class time but still the teacher's edition of both textbooks give teachers useful clues as how to progress.

Another important issue to decide about an EFL textbook is whether it is one single textbook written for specific purpose and specific level of learners or is it a part of a series which are worth using for all the learners at all levels from entry to advance. It would be considered as a plus point for the textbook, if it is part of a series which could accompany the learners as they progress from one level to the other levels. Top Notch Fundamentals A and B are written for beginners but after these two beginning entry levels there are textbooks predicted for other levels from Top Notch 1A to Summit 2B. The same is true for intro i.e. it is a part of a series after which we have Interchange 1 to 3 and the passages which are written for higher-intermediate and advance level learners (under a new title). An advantage of Interchange over Top Notch is that after passing upper intermediate, passages 1 and 2 are designed for advance learners; whereas, the last level of Top Notch is Summit $2 \mathrm{~B}$ and it seems that nothing is predicted for higher levels.

Table 1 represents the results of the checklists which were completed by seven teachers who had the experience of teaching both Top Notch and Interchange. This section is related to the criterion of textbooks' aims and objectives which is composed of four items. The total score for these four items would be 16 .

\section{Table 1}

Aims and Objectives

\begin{tabular}{|c|c|c|c|c|c|c|c|c|c|}
\cline { 2 - 9 } \multicolumn{1}{c|}{} & 1 & 2 & 3 & 4 & 5 & 6 & 7 & Sum & mean \\
\hline Top Notch & 13 & 15 & 14 & 12 & 13 & 14 & 15 & 96 & $13 / 714$ \\
\hline Interchange & 15 & 12 & 9 & 14 & 15 & 12 & 14 & 91 & 13 \\
\hline
\end{tabular}

From the table 1it could be inferred that the raters have almost the same idea about the textbooks objectives. In fact most of the teachers who have the experience of teaching Top Notch and Interchange believe that they are not completely along with their claimed objectives. 


\subsection{General attributes of the textbook}

As it was mentioned, there is no denial that the first and the foremost important step in textbook selection is the investigation of its aims and objectives. After finding those textbooks which parallel our course objectives then it comes to the selection of the most appropriate textbook from several options which are available. In recent years Top Notch has become popular and has been used as the course material by several institutes; however, a walk through the book shops will reveal that interchange after years is still dominating the Iranian EFL market. If we are to choose between these two textbooks with almost the same objectives it is essential to compare their general attributes and physical make up in the first stage since these practical concerns are the first things with which one would be faced when decides to purchase the textbook. To identify and evaluate the practical concerns and general attributes of the textbooks some factors are acknowledged which must be investigated one by one:

1. Is the textbook easily available on the local market?

2. Are the cover's design and colors appealing and attractive?

3. Is the blurb informative? Does it clearly summarize the textbook content and its objectives?

4. Is the textbook page layout appropriate?

5. Are there enough and appropriate non-text (graphical) representations?

Before weighing the practical concerns and giving any explanation regarding the textbooks' physical make-up, I like to appreciate the authors' precision in choosing the appropriate titles for their textbooks. Interchange is titled so, because it aims at providing a change in the realm of teaching and learning so by choosing this textbook series beginners will be changed into skilled international communicators. Top Notch on the other hand is titled so since the authors aim at bringing the students to a Top Notch level of communicative competence.

The first important issue is posed about the availability of Top Notch on the local market. Though Top Notch series are popular and being taught in some institutes, unfortunately it is not easily available on the market. This may not be the case in big cities like Tehran but regarding the local markets there are not much bookshops on which this textbook is available while Interchange series are available in almost all the bookshops around Iran. Since in Iran, usually students are responsible for preparing the textbook, this criterion becomes important in textbook selection.

The next point to be considered is the book's cover which is the first thing we see the moment we pick up a textbook. Top Notch's front cover is not unappealing but the colors used are cold (grey, blue...) while interchange has used a relaxing yellow color for the front book and what is interesting about the choice of color for interchange series is that the learners are thoroughly familiar with the front cover's color of each level of interchange i.e. yellow for the entry level and green for upper intermediate or level3. After considering the front cover, we must definitely check the page layout, font type, graphical representation and the quality of pages in advance, which are influencing factors in the investigation of textbooks' physical make up evaluation. Top Notch fundamentals benefit from interesting four color graphical representations, the font type is appropriate and the pictures are more up-to-dated comparing to Intro Interchange.

It is noteworthy that the colorful pages could be motivating for learners, especially at the beginning levels; however, some pages are more colorful than needed. They are full of pictures and this could be problematic for the learners. Usually when many pictures with different colors are included in one page both the teacher and the learners are confused and even some teachers argue that their eyes are always searching the page to make sure that nothing is left and all the parts are already done. I have to maintain that this could be considered as drawback when textbook pages are crowded with colors and pictures. In Interchange on the other hand, there is a 
Tavakol, M. \& Sayadian, S.

balance between graphic and non- graphic representation.

As regards general attributes, in addition to front cover, back cover which is referred to as blurb, also matters. It is supposed to clearly summarize textbook content, objectives and components. A glance at Top Notch blurb will gives you a clear idea about the textbook's objectives, strategies and components. Also at the up left side LONGMAN Basic dictionary is introduced as a perfect partner to Top Notch Fundamentals and at the bottom the website is addressed for those who want to have an online search about Top Notch series. If you visit the website you could get more information about Top Notch and its second edition with a different cover design. The same is true about Intro. The only difference is that Intro has not addressed a dictionary appropriate to accompany the entry level learners (at this level the learners usually use LONGMAN Basic or Intermediate) and the components are just cited (student's book, workbook, teacher's edition ...), no further guidance is given about each component.

A further point must be made regarding the quality of the pages as an important practical concern. Top Notch is made of high quality glossy papers and it is appealing to the learners but those students who are note takers will have problem with this kind of papers because they cannot write down on them using a pencil and conversely, what is written on the paper could not be easily erased. Here I take a detour to remind that this specific pitfall is not directly related to the textbook and its authors. Finally, it is the cost effectiveness of the textbook package which is important. Though Interchange package (apart from the teacher's manual) is cheaper than Top Notch, the textbooks are both cost effective. The data collected through the checklist is presented in table 2. The maximum score for this section would be 20 .

\section{Table 2}

General attributes

\begin{tabular}{|l|l|l|l|l|l|l|l|l|l|}
\cline { 2 - 9 } \multicolumn{1}{c|}{} & 1 & 2 & 3 & 4 & 5 & 6 & 7 & Sum & mean \\
\hline Top Notch & 18 & 14 & 16 & 12 & 18 & 14 & 17 & 109 & $15 / 571$ \\
\hline Interchange & 19 & 12 & 17 & 18 & 14 & 16 & 19 & 115 & $16 / 428$ \\
\hline
\end{tabular}

According to the above table it seems that from the raters' point of view, Interchange is more appealing than Top Notch. As it was mentioned it is locally available and cost effective which is important for Iranian context where the learners are themselves responsible to purchase the course books; however, we cannot ignore the fact that Top Notch has benefited from perfect colorful illustrations.

\subsection{Textbook content and instructional design}

Textbook content and its instructional design i.e. the scope and sequence of the units, play a pivotal role in the success of a textbook as an indispensable vehicle for foreign language teacher. Considering the instructional design of Top Notch Fundamentals, an important and at the same time positive point is that after the table of content, which is expressive of all the units and reference sections of the book, four pages are devoted to a complete representation of scope and sequence of fundamentals A and B. In this part, the units are introduced by their titles or topics, and there are 8 columns each specifies a section included in each unit. It reveals that in each unit there is practice in vocabulary, conversation, grammar, speaking, pronunciation, listening, reading and writing. These four pages clearly represent the framework of the units included in the textbook and all items which are included in each unit, in other words, they give a gist of the textbook content and its instructional design. Now we must investigate the content of each unit. Fundamentals A and B consists of 14 units i.e. each fundamentals has seven units, each unit provide the learners with three two-page lessons. In the first lesson the unit goals are specified to provide the learners with an idea of what they are able to do with the language by the end of each unit.

New vocabularies are taught audio-visually using color full pictures and high quality audio programs. At the 
end of vocabulary section there is a reference to vocabulary booster which provide the learners with more new vocabularies. There are listening and listening comprehension practice followed by an interesting relevant pop song, and each lesson consists of one quite short conversation which aims at promoting both listening and speaking as well as pronunciation. Grammatical items are taught explicitly in a cognitive approach followed by practice in each item but there is at least one grammatical item in each lesson so we will have at least three grammatical items in each unit and it is difficult for the beginners to internalize them. Unfortunately there is no balance in the use of text and graphical input (illustrations) in a way that each lesson is full of pictures which attract the learners and can easily distract them. After each unit there are Top Notch activities which aim at providing the learners with further practice and there is a unit warp-up which remind the learners about the cited goals of the unit. In the reference section including vocabulary booster there are more language input for those learners willing to learn more.

Intro, on the other hand, is indicative of a fairly straightforward instructional design which is easy to administer. It includes an important page useful for both teacher and learners which is ignored in Top Notch and many other EFL textbooks. This page is titled as classroom language which can be very useful specifically for the beginning level learners. This provides the learners with opportunity to learn the most used statements and the most frequent questions in an EFL classroom. Teacher, depending on the learners and classroom situation are free to add some more useful statements; besides, it gives them a clue as how to start the first session with an intriguing warm up. Intro has presented the learners and teachers with plan of Intro book exactly like Top Notch. The book plan shows that it consists of 16 units and usually each four units are taught during one semester. The units are introduced with topics or titles and the other five columns introduce all the unit components and skill which will be practiced during each unit. Unlike Top Notch in which the units are divided to three lessons, Intro units are divided into sections with all sections following specific goal(s). In each unit there are at least two conversations which are considered to be useful in promoting learners listening and speaking with some grammatical points in each conversation intended to provide the learners with purposeful daily use of the grammatical structures. In this regard both interchange and Top Notch could be considered as having the same features. Another similarity between the aforementioned textbooks in terms of their content is that they are not gender, ethnic or culturally biased. Pictures used in the textbooks represent different people of both sexes from all ethnic groups.

A big difference between Top Notch and Interchange is in the balanced use of text and colorful pictures in Interchange. An important section of Intro is snapshot which is absent in Top Notch. Snapshots provide the learners with relevant cultural information to promote learners pragmatic competence. As well as conversation there are several listening comprehension practices in each lesson. Like Top Notch grammar is taught deductively in a cognitive approach following examples and exercises. The only difference is that each unit consists of two grammatical points which are easier for the learners to learn and internalize. Vocabularies are taught audio-visually and in meaning full contexts. Just the same as Top Notch, one section of each unit is dedicated to pronunciation practice.

There are two distinguishing aspects of Interchange instructional design which give it superiority over Top Notch: first of all, In Intro each unit will give reference to a related Interchange activity at the end of the book which provides the learners with further practice in vocabulary and structure which could be more useful and practical than Top Notch vocabulary booster. On the other hand, at the end of each unit there are progress checks similar to Top Notch activity, but this progress check begins with self-assessment intended to provide the learners with opportunity check their progress in advance and systematic activities to practice what has been taught. Intro also includes self-studies at the end of the book for progress assessment.

A useful part of Top Notch which is not predicted in Intro is the manual for take-home audio CDs which provide the learners and teachers with helpful hints as how to use the CDs and what tracks are included; however, it must be mentioned that Iranian learners rarely benefit from these kinds of information since they seldom read them at all, so it could be considered as a merit of Top Notch but not approved as a demerit of Intro. Points are 
Tavakol, M. \& Sayadian, S.

already mentioned to compare Top Notch and Interchange instructional design, but it is not out of merits to bring the teachers perspectives reflected via total scoring to the textbooks' instructional design.

Table 3

Textbooks' instructional design

\begin{tabular}{|l|l|l|l|l|l|l|l|c|c|}
\cline { 2 - 9 } \multicolumn{1}{c|}{} & 1 & 2 & 3 & 4 & 5 & 6 & 7 & Sum & mean \\
\hline Top Notch & 23 & 26 & 22 & 20 & 23 & 22 & 25 & 161 & 23 \\
\hline Interchange & 20 & 22 & 26 & 19 & 25 & 22 & 21 & 155 & $22 / 142$ \\
\hline
\end{tabular}

Almost all the teachers have the same idea about the textbook's instructional design that although not perfect but still appropriate in terms of providing the learners with sufficient communicative and pragmatic input. Only one teacher has rated the textbooks' content exactly the same.

\subsection{Vocabulary:}

Vocabulary is considered to be an important language input which helps the learners to promote other skills. An influencing feature of a textbook is the way new vocabularies are classified and presented. In the checklist questions are asked about the way vocabulary is presented to the learners and the techniques used for vocabulary recycling in subsequent units. Talking about Top Notch, new vocabularies are presented audio-visually and this kind of vocabulary learning would promote learner's listening skills as well. The learners will hear the correct spoken form of the words and practice in aurally recognizing vocabulary and it will develop facility in comprehending spoken massage, while at the same time helps the learners to promote their speaking skills.

Both textbooks provide the learners with references and activities to learn more vocabularies and another important point is that vocabulary is presented aurally and practiced in meaningful contexts. A demerit of the aforementioned textbooks is that no techniques are used for extended vocabulary recycling to reinforce the learnt vocabularies as it is claimed. So it can be concluded that both textbooks have treated vocabulary learning in approximately the same way.

\subsection{Grammar}

An important part of language learning is learning the structure of the language and more important is the way which the structure is presented to the learners. In Top Notch and Interchange the grammar is presented explicitly in a cognitive approach, say, deductively (move from rule to example). After presenting the core grammar, the learners are supposed to do the following exercises and the grammatical structures are used in conversations and meaningful contexts throughout the unit. The only problem regarding Top Notch grammar which was mentioned before is that as much as three or four grammatical items are covered in each unit. Even some teachers believe that Top Notch Fundamentals parallel level 1 of Interchange and I think that this is partially true. It seems that Fundamentals are not exactly addressed to beginners as it is claimed. On the other hands Intro will provide the learners with an opportunity to progress slowly from entry level to levels 1, 2 and 3. Table 3 represents the scores obtained in regards with vocabulary and grammar using the related checklist to entail the raters' judgment.

Table 4

Vocabulary and Grammar

\begin{tabular}{|l|c|c|c|c|c|c|c|c|c|}
\cline { 2 - 9 } \multicolumn{1}{c|}{} & 1 & 2 & 3 & 4 & 5 & 6 & 7 & Sum & mean \\
\hline Top Notch & 17 & 18 & 20 & 14 & 15 & 17 & 15 & 116 & $16 / 571$ \\
\hline Interchange & 16 & 14 & 17 & 18 & 17 & 18 & 20 & 120 & $17 / 142$ \\
\hline
\end{tabular}


It is obvious from this table and the previous ones that most of the teachers have the same idea about the textbooks features and there is slight difference which could be ignored but still we have to be aware that in some cases these slight differences have considerable influence on the total process of teaching and learning. If we take 20 as the optimum score, Interchange is scored higher than Top Notch. An important fact which must be borne in mind is that not a long time has passed since Top Notch entered in the realm of EFL teaching and learning, so it could be deduced that the teachers are not much experienced in teaching these series. According to the table and what has been mentioned in this section, it could be identified that although both textbooks have recognized and treated grammar and vocabulary in the same way, Interchange has been more successful to provide the learners with opportunities to promote both depth and breadth of vocabulary and grammar.

\subsection{Listening}

Speaking does not of itself constitute communication unless what is being said is comprehended by another person, interlocutor, so teaching the comprehension of spoken language is of primary importance if the communication aim is to be achieved (Rivers 1981). Generally an important criterion in textbook evaluation is its treatment toward the four major skills of listening, speaking, reading and writing. The first and foremost skill which is usually ignored by teachers and learners is listening skill. A highlighting feature of Top Notch as an EFL textbook is its vigor in promoting the learner's listening skills. Several parts are devoted to reinforce listening comprehension, from vocabulary learning to conversation practice; however, a more prominent feature is the attention paid to rhythm and intonation to optimize learner's pronunciation in a way that after each conversation there is an intonation practice.

Reinforcing listening comprehension skills is of utmost importance in Iranian EFL context in which teachers are not natives and learners have serious problems in comprehending the spoken language. They can take the audio program as their model of a native speaker and correct pronunciation, instead of teacher. Interchange is also an applicable textbook in promoting learner's listening as it is claimed by Jack C. Richards but unfortunately there may be some weak points such as the lack of enough practice in rhythm and intonation and songs which are helpful and motivating for the learners are not predicted in textbook's audio component. Another issue is posed regarding listening is that in these textbooks as well as listening parts in which learners try to listen and repeat or listen and practice, there is a listening comprehension exercises in which the learners are supposed to recognize and produce answers such as completing the chart after listening. In Iran usually these listening comprehension sections are transcribed to serve a practice in both listening and writing.

\subsection{Speaking}

Speaking is an essential component of interactive communication and in fact the main objective of the learners who attend general English courses. Students come to study of another language with the strong conviction that language means something spoken and the early introduction of the speaking of the language is also important for reasons of motivation. A substantial feature of a good EFL textbook is taking advantage of dialogues to facilitate speaking ability of the learners. The dialogues in textbooks could mostly be classed as conversation facilitation dialogue or grammar demonstration dialogues. The conversation facilitation dialogue provides students with immediately useful segments of language, with which they can begin to communicate.

The dialogues in Top Notch are conversation facilitation to provide useful materials for student to student communication and they are often memorized and then there would be role play in class to promote their speaking ability. It must be mentioned that they usually include those structures which are taught in each lesson and it has the benefit of presenting the students with meaningful use of the structures they have learned in daily conversation, but it is completely upon the teacher not to use a conversation facilitation dialogue, which must be memorized to serve as a useful language segment for students, to teach grammatical items. Intro on the other hand has provided the learners with the same type of dialogues to facilitate the learners speaking ability. Though 
Tavakol, M. \& Sayadian, S.

the author has mentioned that the conversations are natural, fun dialogue that introduces new grammar, they are usually memorized by the learners to provide them with useful segments of the language. Comparing to Top Notch, Intro consists of more pair and group works which provide the opportunity of student to student communication in the classroom. Interchange activities also are embedded in the book for the same purpose.

\subsection{Reading and writing}

Where communication is the main objective, it is essential that the bulk of class time be devoted to aural-oral practice, to provide plenty of listening opportunities and to eliminate the student's early inhabitations against expressing themselves in the medium of language. From the first time when the written form of the language i.e. script, is introduced the learners should be encouraged to read directly in the language without translation. The introduction of reading permits the introduction of some writing exercises. Reading and writing reinforce each other and consolidate the aural-oral learning. It must be mentioned that reading is sometimes referred to as a passive skill, but if the textbook provide the learners with enough practice in fluent direct reading with comprehension of meaning it is clear that the readers are far from passive during this activity. According to Goodman fluent reading is a psycholinguistic guessing game. An important feature of a textbook is its use of authentic reading materials and varied writing exercises.

Looking at Top Notch scope and sequence you will find that reading and writing are brought together in one column to show that they reinforce each other. Top Notch has consistently used authentic reading materials mostly taken from newspaper sections and articles. Following the reading sections there are varied written exercises. In parallel, Interchange has also provided the learners with written exercises of different types. An advantage of Top Notch in relation to reading and writing is that the learners will be faced with written materials of different types so they become familiar with different types of writing, in addition the written exercises are logically sequenced from writing down or notation to reproduction, in other words, they start from writing proper and common names or writing down telephone numbers after listening to write directions or answering questions after a reading comprehension passage and later to guided writings such as comparing things and finally it comes to expressive writing exercises e.g. descriptions, biographies and suggestions.

The same process could be found in Intro plan but it is more guided and the learners move toward writing descriptions in different tenses from present to past and future in a slower pace which is appropriate for beginners. Again it must be noted that although written exercises in Intro are more logically sequenced, they are treated almost identical in the textbooks in a way that in unit seven of both textbooks there is a writing exercise in which the learners are supposed to write about a dream house preceding a reading passage about different houses. Other teachers' evaluation of the textbook effectiveness in promoting four major skills is presented in table 4.

Table 5

Four major skills

\begin{tabular}{|l|c|c|c|c|c|c|c|c|c|}
\cline { 2 - 10 } \multicolumn{1}{c|}{} & 1 & 2 & 3 & 4 & 5 & 6 & 7 & Sum & mean \\
\hline Top Notch & 16 & 18 & 22 & 21 & 23 & 19 & 20 & 139 & $23 / 166$ \\
\hline Interchange & 19 & 21 & 19 & 19 & 18 & 22 & 22 & 140 & $23 / 33$ \\
\hline
\end{tabular}

There could be no need to explain that the little difference in the scores is expressive of the teachers same opinion, in general, about textbooks' contribution to the learners' four major skills, but textbooks differences regarding the skills are already mentioned in details by the end of each section.

\subsection{Exercises and activities}

An important criterion for textbook evaluation is the kind of exercises and activities predicted to promote 
learning process. A utilizing exercise or activity will provide the learners with the opportunity for critical thinking, problem solving and reasoning. It must be challenging to motivate the learners and varied in format not to become boring. Another issue to be considered is the balance between controlled and free exercises in each unit.

Top Notch fundamentals have provided the learners with a plethora of different types of exercises each aims at promoting specific skill(s), and even they have the benefit of using computer and internet in the class for on line practice. From this aspect Fundamentals are more attractive for the beginners comparing to Intro. Opening fundamentals A and having a look at the first unit you will see that the first lesson is started with teaching of vocabulary via listening and then there is a reference to vocabulary booster to provide the learners with more vocabulary and further practice, immediately followed by a listening comprehension exercise which is a controlled practice since there would be only comprehension and no production in the side of the learners. After grammar also there is controlled grammar practice followed by controlled reading and writing practice. The same procedure is repeated in the subsequent lessons even in the pair works the answers are controlled and there is not much production by the learners but as we go through the subsequent units there are much production and comprehension-production practice. There is Top Notch activities by the end of each unit, also fourteen easy-to-administer and easy-to-score unit achievement tests which accompany the textbook. In addition to the photocopiable achievement tests, two review tests provide additional cumulative assessment.

Now let's consider the first units of Intro. Right from the beginning there are easy to do, production and comprehension-production exercises which are repeated through subsequent chapters. on page 2, For instance, below the snapshot there are questions, the second and the third questions (who are some famous people with these names?) are easy to answer, challenging (the learners think and try to provide the class with famous names they know to show the other their general knowledge of the world), learner initiating and a type of guided practice. From the beginning, also there are lots of pair and group works. By the end of each two chapters there is a progress check containing a subjective self-assessment which help the learners to wrap up what they has learned throughout the units. Each unit will give a reference to extra activities in Interchange activities at the end of the book which useful in providing the learners with further practice. Top Notch does not include such kind of extra activities, but a reference is given to the vocabulary booster as an extra source of vocabulary learning. In Intro the last pages of the student book is devoted to self-study related to each unit accompanied by listening activities.

\section{Table 6}

Exercises and activities

\begin{tabular}{|l|c|c|c|c|c|c|c|c|c|}
\cline { 2 - 9 } \multicolumn{1}{c|}{} & 1 & 2 & 3 & 4 & 5 & 6 & 7 & Sum & mean \\
\hline Top Notch & 18 & 23 & 26 & 27 & 25 & 21 & 25 & 165 & $23 / 571$ \\
\hline Interchange & 27 & 24 & 23 & 24 & 20 & 19 & 24 & 161 & 23 \\
\hline
\end{tabular}

Table 5 shows that teachers more or less have the same idea about the activities and exercises provided by the textbooks, but indubitably the differences which are not apparent from checklist score and seem to be trivial would contribute a great deal to the teaching and learning process. Consequently it must be mentioned that both textbooks have tried to provide the learners with enough guided practice of all skills and progress check quizzes, but Intro exercises are more learner initiating, production oriented, challenging and varied. It provides the learners with a slow, unconscious progress and there is a balance in the use of free vs. controlled activities and exercises. The only drawback regarding Intro is that it lacks good speaking tests to provide the teacher and the learner with speaking ability assessment.

\subsection{Supplementary materials}

A textbook is not the only thing needed for an EFL classroom where no native speakers are available and the 
Tavakol, M. \& Sayadian, S.

language is not spoken anywhere but in the classroom. For this reason, all EFL textbooks are equipped with supplementary materials. As well as student's book with take home CDs, Top Notch complete package consists of teacher's edition and lesson planer, a tightly linked workbook, complete classroom audio program with high quality and as perfect companion for textbook, complete assessment package, Top Notch TV consisting of high quality, lively and entertaining videos plus unrehearsed interviews with English speakers around the world with activity worksheets and booklet and finally a companion website. The only problem with Top Notch is that the teacher's edition is not easily available. In turn, Intro also has components other than the student book and take home CDs such as a workbook which is apart from the student book and in this regard the tightly close workbook of Top Notch is preferred. Unlike Top Notch, the teacher's edition is easily available comparing to Top Notch's. The class audio and video programs and the related video activity books are also valuable.

\section{Table 7}

Supplementary materials

\begin{tabular}{|l|l|l|l|l|l|l|l|l|l|}
\cline { 2 - 9 } \multicolumn{1}{c|}{} & 1 & 2 & 3 & 4 & 5 & 6 & 7 & Sum & mean \\
\hline Top Notch & 15 & 13 & 16 & 16 & 15 & 16 & 16 & 107 & $15 / 285$ \\
\hline Interchange & 12 & 14 & 11 & 14 & 16 & 14 & 13 & 94 & $13 / 428$ \\
\hline
\end{tabular}

Table 6 shows that the teachers are more satisfied with Top Notch than Interchange Supplementary materials, why is this so? Comparing to Intro, Top Notch is appreciable for its beneficial and complete audio and video program. They are of high quality and attractive to the learners while Intro is weak in this regard and the videos are out of date and in some parts difficult to understand with lower quality. Top Notch, on the other hand, is accompanied by pop songs and pop karaoke relevant to some unit lessons, Intro teachers must choose unrelated pop songs which are sometimes above the level of the learners. Of course it must be mentioned that the school teachers usually do not spend much time on audio programs instead they prefer their students to improve their knowledge of vocabulary and grammar. Another section which interchange lacks is the online activities addressed by Top Notch, at the companion website. This section will provide the learners with the opportunity to practice online using computer so the exercises will not be boring and a part of class time could be devoted to game play. The last point is posed about Top Notch assessment program which is complete and beneficial comparing to Intro.

\section{Conclusion}

As mentioned, the main purpose of this study was to provide a valid evaluation of Top Notch as an EFL textbook to be used in general four-skill courses in Iranian EFL context. This textbook is very attractive for the beginning level learners because of the extensive use of high quality pictures and audio-visual aids. A comparison between Top Notch Fundamentals and Intro reveals that in most parts Top Notch is the same as Intro. Top Notch's total score from the checklists is $130 / 878$ and 128/47 for Intro, so the aforementioned textbooks could be both recommended for an EFL communicative course. We cannot ignore the fact that Top Notch has its merits for Iranian EFL learners and contains some sections which are ignored in Intro and other parallel textbooks; however, unfortunately it does not lead the learners in a normal pace of progress and logical sequence to the upper levels i.e. it is not really addressed for true beginners. With all its deficiencies and with considering the fact that it is not completely along with the objectives it claims, Interchange is still recommended to be used by institute instructors and school teachers and could not be easily replaced by other available EFL textbooks. Top Notch is also appropriate to be used in institutes but, since the only important advantage of Top Notch over Intro is its strong audio visual aids and listening practice and school teachers do not spend much time on listening practice, it is not appropriate to be used in schools. 


\subsection{Limitations of the study:}

There are several limitations with this descriptive study. First of all, we have conducted the study based on a self-developed checklist the reliability of which is not investigated. Secondly, it must be mentioned that the data is self-reported and seemingly subjective. A further point is that Top Notch has started to be taught not for so long and the teachers who are asked to complete the checklist are not equally experienced in teaching Top Notch and Intro Interchange. Also some institutes which were known for teaching Top-Notch series did not allow us to distribute the checklists among their teachers (who had certainly the experience of teaching Interchange) because they were afraid of their textbook's validity and applicability going under question! Then we were forced to carry out the study with seven teachers who were available and had the experience of teaching both Top Notch and Interchange.

\section{References}

Ansary, H., \& Babaii, E. (2002). Universal characteristics of EFL/ESL textbooks: A step towards systematic textbook evaluation. The Internet TESL Journal, 8(2), 1-9.

Birjandi, P., \& Alizadeh, I. (2012). Manifestation of critical thinking skills in the English textbooks employed by language institutes in Iran. International Journal of Research Studies in Language Learning, 2(1).

Chall, J. S., Conard, S. S., \& Harris-Sharples, S. (1991). Should textbooks challenge students? The case for easier or harder textbooks: Teachers College Press.

Holmes, J. (1988). Doubt and certainty in ESL textbooks. Applied linguistics, 9(1), 21-44. http://dx.doi.org/10.1093/applin/9.1.21

Lesikin, J. (2001). Potential Student Decision Making in Academic ESL Grammar Textbooks. Linguistics and Education, 12(1), 25-49. http://dx.doi.org/10.1016/S0898-5898(00)00042-5

Litz, D. R. (2005). Textbook evaluation and ELT management: A South Korean case study. Asian EFL journal, 6(4), 27-38.

Mikk, J. (2000). Textbook: Research and Writing. Baltische Studien zur Erziehungs und Sozialwissenschaft, Band 3 (Baltic Studies for Education and Social Sciences, Volume 3): ERIC.

Porreca, K. L. (1984). Sexism in current ESL textbooks. TESOL quarterly, 18(4), 705-724. http://dx.doi.org/10.2307/3586584

Rivers, W. M. (1987). Interactive language teaching: Cambridge University Press.

Rivers, W. M., \& Temperley, M. S. (1978). A Practical Guide to the Teaching of English as a Second or Foreign Language: ERIC.

Sahragard, R., Rahimi, A., \& Zaremoayeddi, I. (2009). An in-depth evaluation of interchange series. Porta Linguarum: revista internacional de didáctica de las lenguas extranjeras (12), 37-54.

Soleimani, H., \& Dabbaghi, A. (2012). Textbook evaluation: A reflection on the New Interchange Series. International Journal of Research Studies in Language Learning, 1(2). http://dx.doi.org/10.5861/ijrsll.2012.v1i2.70

Stein, M., Stuen, C., Carnine, D., \& Long, R. M. (2001). Textbook evaluation and adoption. Reading and Writing Quarterly, 17(1), 5-23. http://dx.doi.org/10.1080/105735601455710

Tulley, M. A. (1985). A Descriptive Study of the Intents of State-Level Textbook Adoption Processes. Educational Evaluation and Policy Analysis, 24(3), 289-308

Williams, D. (1983). Developing criteria for textbook evaluation. ELT journal, 37(3), 251-255.

http://dx.doi.org/10.1093/elt/37.3.251 
Tavakol, M. \& Sayadian, S.

\begin{tabular}{|c|c|c|c|c|c|}
\hline \multicolumn{6}{|l|}{ Appendix } \\
\hline 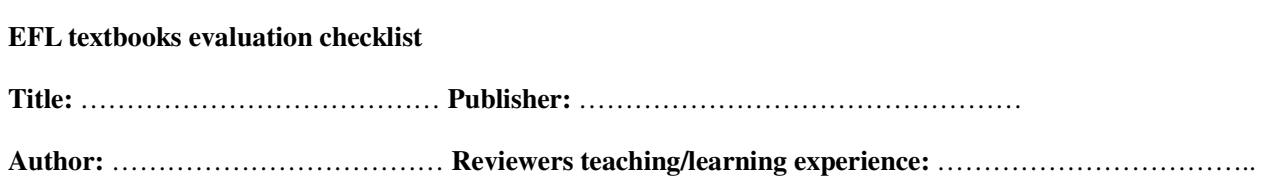 & 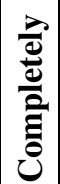 & $\stackrel{\theta}{\Xi}$ & 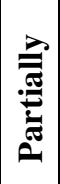 & $\stackrel{\circ}{Z}$ & 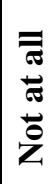 \\
\hline \multicolumn{6}{|l|}{ A: General attributes } \\
\hline 1- Is the textbook available on the local market? & 4 & 3 & 2 & 1 & 0 \\
\hline 2-Is the textbook's package cost effective? & 4 & 3 & 2 & 1 & 0 \\
\hline 3-Are the cover's design and colors attractive and motivating for the learner? & 4 & 3 & 2 & 1 & 0 \\
\hline 4-Are the font type, size, weight, and the quality of papers are appealing? & 4 & 3 & 2 & 1 & 0 \\
\hline 5-Is the blurb informative? Does it clearly summarize the textbook content and its objectives? & 4 & 3 & 2 & 1 & 0 \\
\hline \multicolumn{6}{|l|}{ B: Aims and objectives } \\
\hline $\begin{array}{l}\text { 6-Are a sufficient number of course objectives explicitly addressed by the textbook? Do they coincide with } \\
\text { course objectives? }\end{array}$ & 4 & 3 & 2 & 1 & 0 \\
\hline $\begin{array}{l}\text { 7-Is the textbook appropriately addressed to learners with specific age and level according to a standard grading } \\
\text { system? }\end{array}$ & 4 & 3 & 2 & 1 & 0 \\
\hline 8-Does the textbook aim at promoting learner's communicative and pragmatic competence? & 4 & 3 & 2 & 1 & 0 \\
\hline 9-Is the textbook flexible enough to allow different teaching and learning styles? & 4 & 3 & 2 & 1 & 0 \\
\hline \multicolumn{6}{|l|}{ C:Texbook content } \\
\hline 10-Is the content systematically organized in terms of topics or functions? & 4 & 3 & 2 & 1 & 0 \\
\hline 11-Are the units short enough to provide the learners with a sense of progress? & 4 & 3 & 2 & 1 & 0 \\
\hline 12-Is there a balanced integration of text and graphic (non-text content)? & 4 & 3 & 2 & 1 & 0 \\
\hline 13- Are cultural sidebars used to provide the learners with cultural information? & 4 & 3 & 2 & 1 & 0 \\
\hline 14-Are techniques used to encourage group work (e.g. dialogues)? & 4 & 3 & 2 & 1 & 0 \\
\hline $\begin{array}{l}\text { 15-Are all the aspects of phonological system covered: individual sounds, syllable structure, word stress, } \\
\text { sentence stress, intonation? }\end{array}$ & 4 & 3 & 2 & 1 & 0 \\
\hline 16-Is the content free from cultural, ethnic, and gender bias? & 4 & 3 & 2 & 1 & 0 \\
\hline \multicolumn{6}{|l|}{ D: Vocabulary and Grammar } \\
\hline 17-Is vocabulary presented in a functional and/or meaningful context? & 4 & 3 & 2 & 1 & 0 \\
\hline 18-Are new vocabulary items reinforced through recycling in subsequent lessons? & 4 & 3 & 2 & 1 & 0 \\
\hline 19-Are grammatical explanations clear and contextualized? & 4 & 3 & 2 & 1 & 0 \\
\hline 20-Is there a balance in the treatment of form and use? & 4 & 3 & 2 & 1 & 0 \\
\hline 21-Does the textbook promote both breadth and depth of vocabulary and grammar? & 4 & 3 & 2 & 1 & 0 \\
\hline \multicolumn{6}{|l|}{ E: Four major skills } \\
\hline 22-Is there a balanced practice in all four skills (listening, speaking, reading, and writing)? & 4 & 3 & 2 & 1 & 0 \\
\hline 23-Does the textbook contain authentic reading material at an appropriate level? & 4 & 3 & 2 & 1 & 0 \\
\hline 24-Is listening material well recorded and authentic? & 4 & 3 & 2 & 1 & 0 \\
\hline 25-Is material for spoken language well designed to equip the learners for interaction? & 4 & 3 & 2 & 1 & 0 \\
\hline 26-Does the textbook promote writing skills in terms of degree of accuracy? & 4 & 3 & 2 & 1 & 0 \\
\hline $\begin{array}{l}\text { 27-Does the textbook pays attention to sub-skills i.e. bottom up vs. up down strategies, skimming and scanning } \\
\text { for information, etc? }\end{array}$ & 4 & 3 & 2 & 1 & 0 \\
\hline \multicolumn{6}{|l|}{ F: Exercises and activities } \\
\hline 28-Do the exercises and activities promote critical thinking, problem solving, and reasoning? & 4 & 3 & 2 & 1 & 0 \\
\hline 29-Does the textbook contain self-assessment tests and quizzes for progress check? & 4 & 3 & 2 & 1 & 0 \\
\hline 30-Do the activities allow students to personalize their responses and/or provide their own meaning? & 4 & 3 & 2 & 1 & 0 \\
\hline 31-Are the exercises progressive as the students move through the textbook? & 4 & 3 & 2 & 1 & 0 \\
\hline 32-Do the exercises vary in format to be continually motivating and challenging? & 4 & 3 & 2 & 1 & 0 \\
\hline $\begin{array}{l}\text { 33-The textbook provides a balance of controlled vs. free exercises and tasks that focus on both fluent and } \\
\text { accurate production? }\end{array}$ & 4 & 3 & 2 & 1 & 0 \\
\hline $\begin{array}{l}\text { 34-Are relevant exercises included in the textbook to provide the learners with sufficient practice to reinforce } \\
\text { and retain what is being taught? }\end{array}$ & 4 & 3 & 2 & 1 & 0 \\
\hline \multicolumn{6}{|l|}{ G: Supplementary materials } \\
\hline 35-Is the textbook's package accompanied with facilitative, high quality audio-visual aids? & 4 & 3 & 2 & 1 & 0 \\
\hline 36-Is the teacher's edition available with the resource package? & 4 & 3 & 2 & 1 & 0 \\
\hline $\begin{array}{l}\text { 37-Is the teacher's manual written in a comprehensible manner with clear instructions to help the less } \\
\text { experienced teachers? }\end{array}$ & 4 & 3 & 2 & 1 & 0 \\
\hline $\begin{array}{l}\text { 38-Does the package contain extra aids like work book and activity book, movies, songs, games, flash c } \\
\text { story books, video activity book etc? }\end{array}$ & 4 & 3 & 2 & 1 & 0 \\
\hline
\end{tabular}

